\title{
The stereoselective degradation and molecular ecological mechanism of chiral pesticides beta-cypermethrin in soils with different $\mathrm{pH}$ values
}

\author{
Zhong-Hua Yang ${ }^{\mathrm{a}, \mathrm{b}}$ Guo-Dong $\mathrm{Ji}^{{ }^{\mathrm{a}}}$ * \\ ${ }^{\text {a }}$ Key Laboratory of Water and Sediment Sciences, Ministry of Education, Department of \\ Environmental Engineering, Peking University, Beijing, 100871, China \\ ${ }^{\mathrm{b}}$ Department of Plant Protection, College of Plant Sciences and Technology, Huazhong \\ Agricultural University, Wuhan, 430070, China
}

*Correspondence: G D Ji, Key Laboratory of Water and Sediment Sciences, Ministry of Education, Department of Environmental Engineering, Peking University, Beijing, China.

E-mail: jiguodong@pku.edu.cn

Supplementary information: There are 13 supplementary figures and 5 supplementary tables.

The number of pages are 19. 


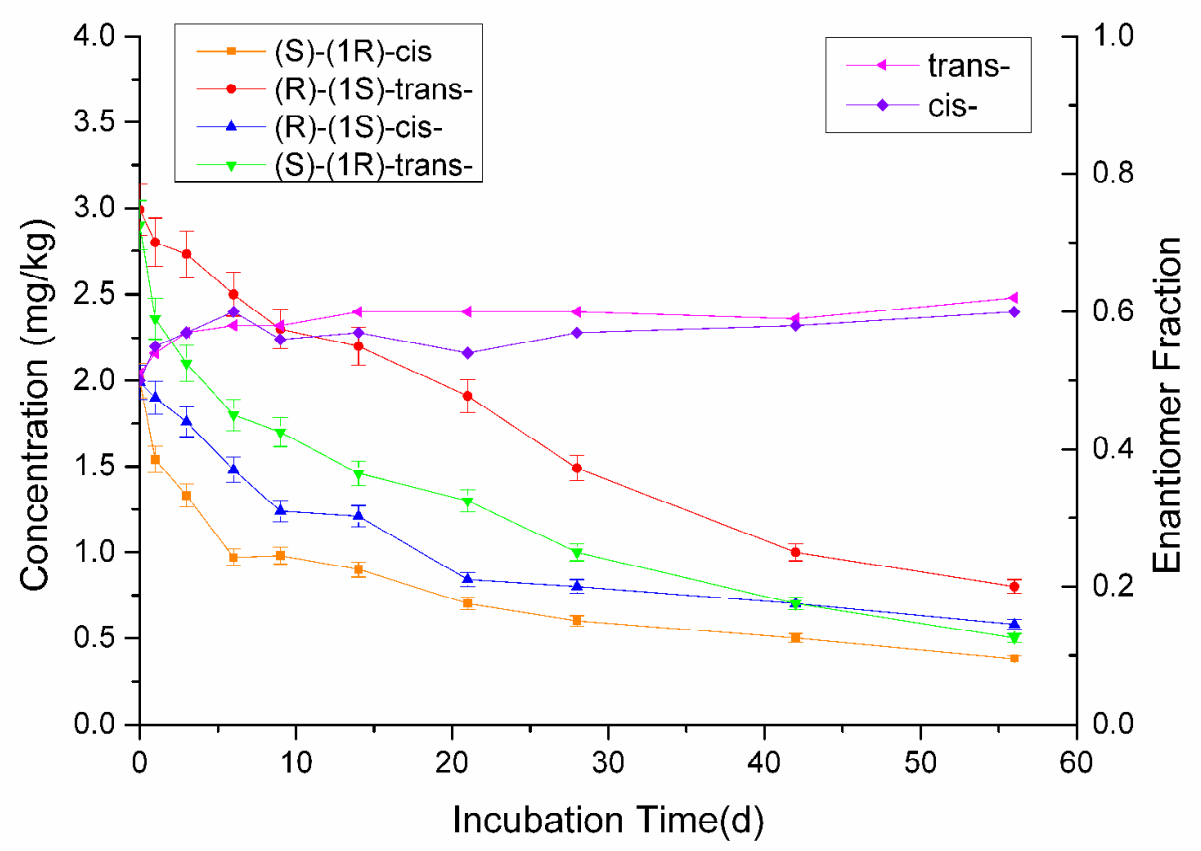

Fig. S1 The degradation of spiked BCYM in Beijing unsterilized soils. The concentrations and Enantiomer Fraction values of BCYM versus incubation time in the $10 \mathrm{mg} / \mathrm{kg}$ spiked soil. 


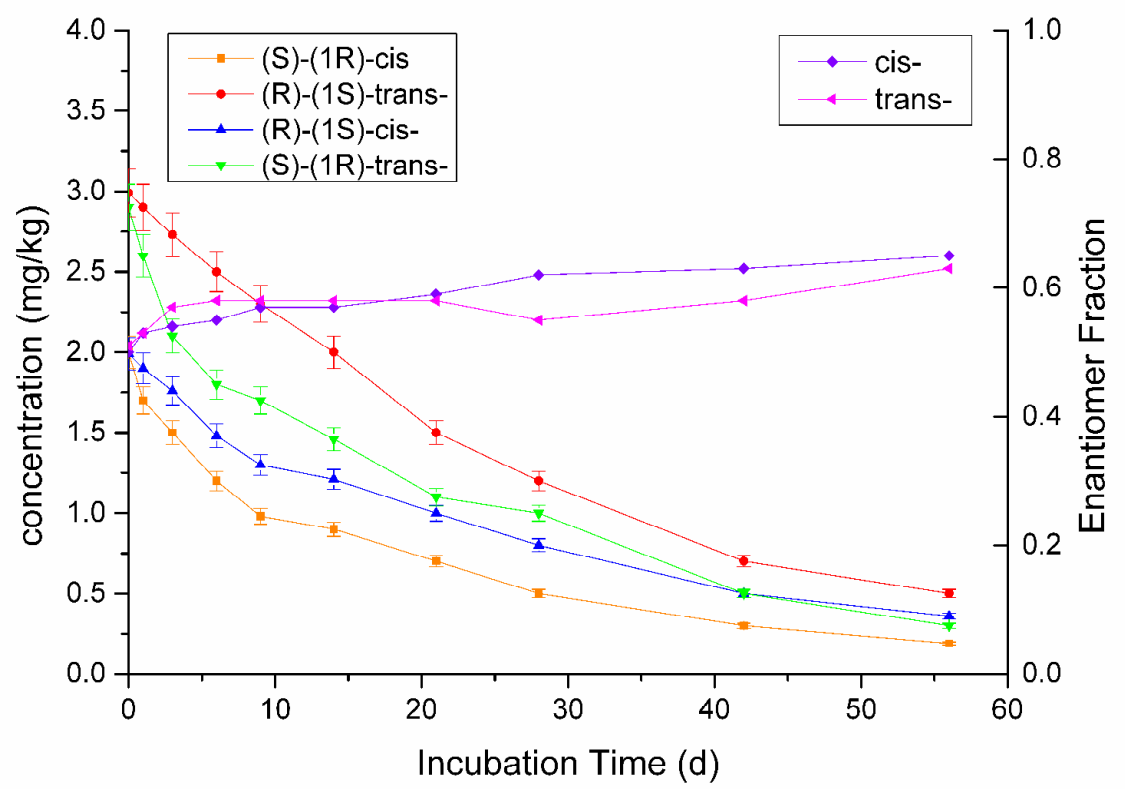

Fig. S2 The degradation of spiked BCYM in Changchun unsterilized soils. The concentrations and Enantiomer Fraction values of BCYM versus incubation time in the $10 \mathrm{mg} / \mathrm{kg}$ spiked soil. 


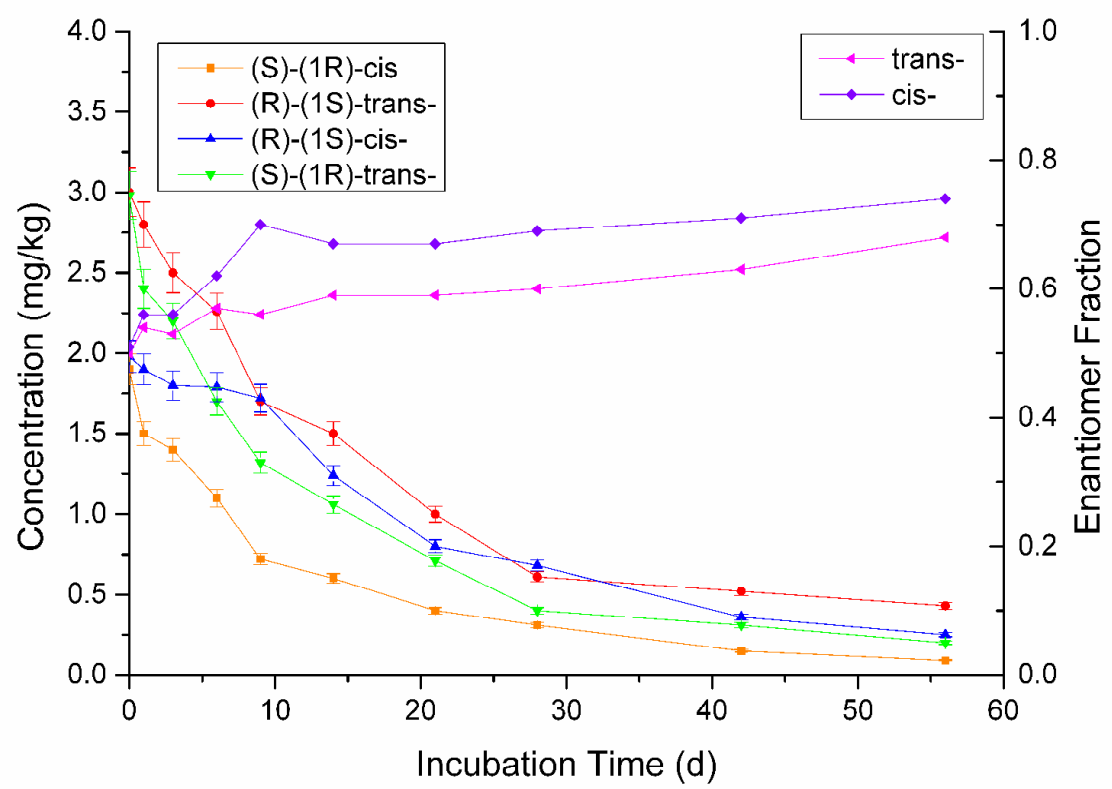

Fig. S3 The degradation of spiked BCYM in Fuling unsterilized soils. The concentrations and Enantiomer Fraction values of BCYM versus incubation time in the $10 \mathrm{mg} / \mathrm{kg}$ spiked soil. 

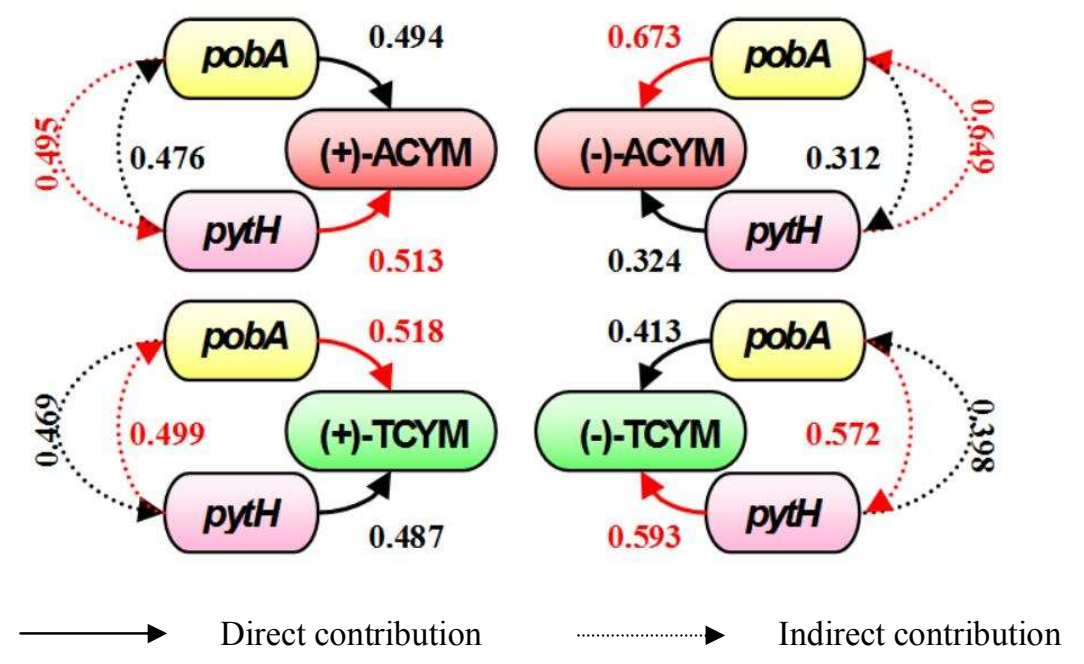

Fig. S4 The direct and indirect contributions of key rate-limiting functional genes on the degradation of the four isomers in Changchun soil. 

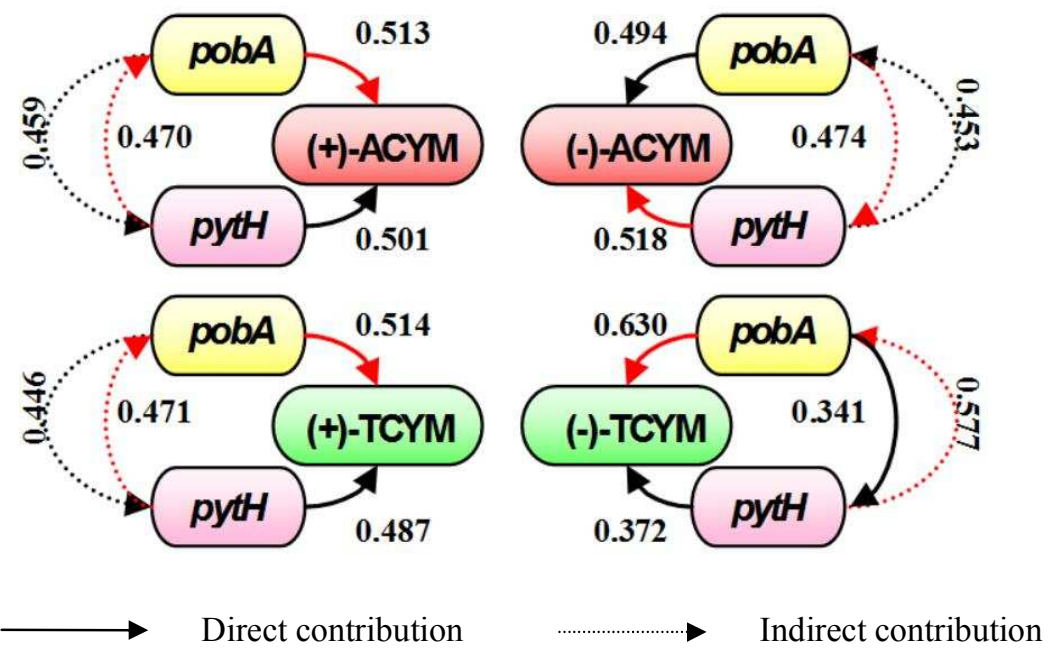

Fig. S5 The direct and indirect contributions of key rate-limiting functional genes on the degradation of the four isomers in Beijing soil. 

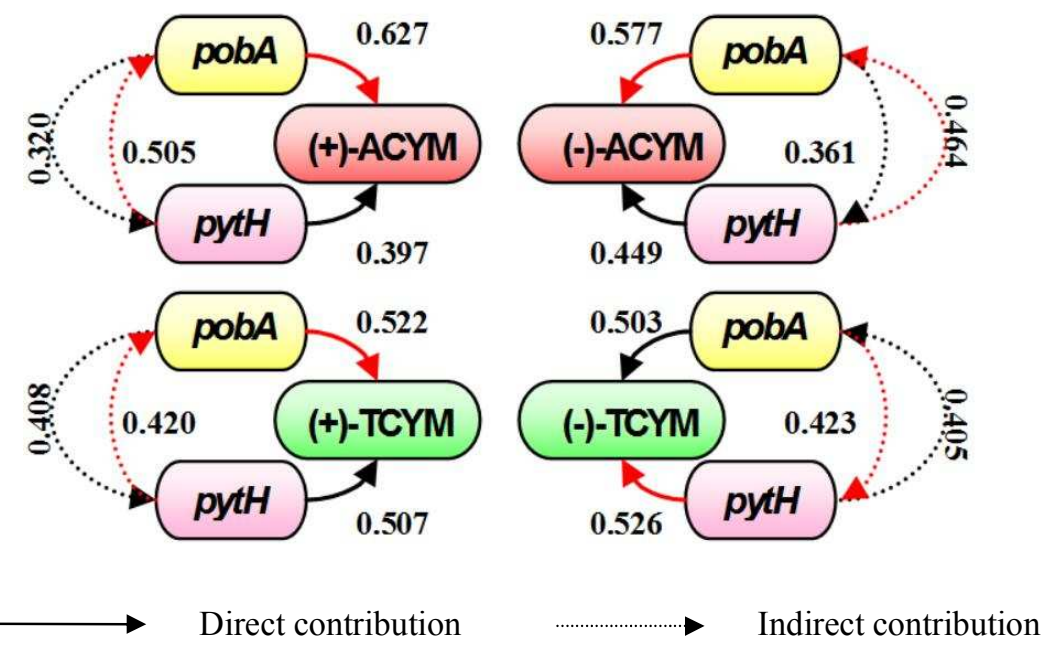

Fig. S6 The direct and indirect contributions of key rate-limiting functional genes on the degradation of the four isomers in Fuling soil. 

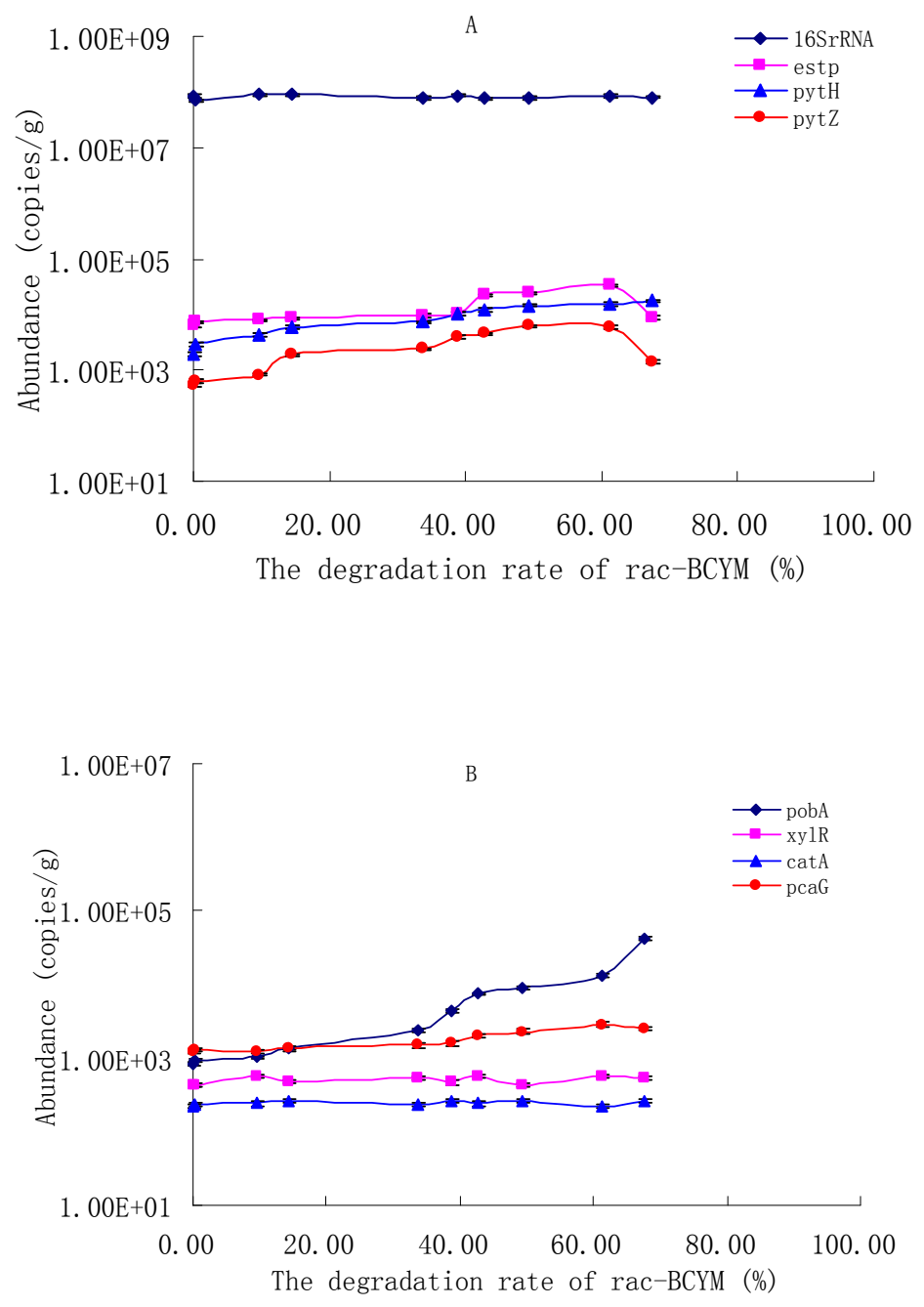

Fig S7: Absolute abundances of bacterial 16S rRNA and functional genes in Beijing soil 

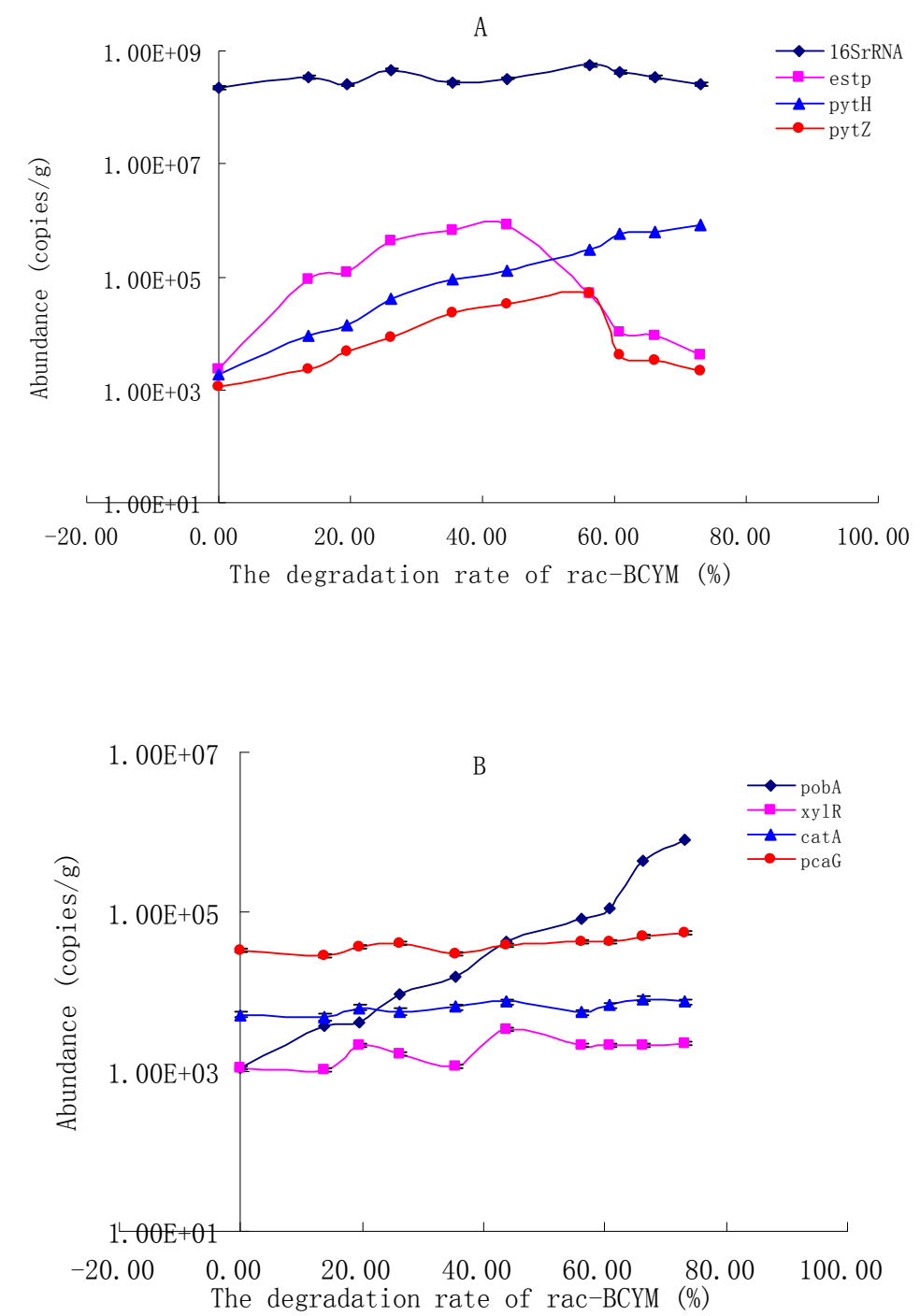

Fig S8: Absolute abundances of bacterial 16S rRNA and functional genes in Changchun soil 

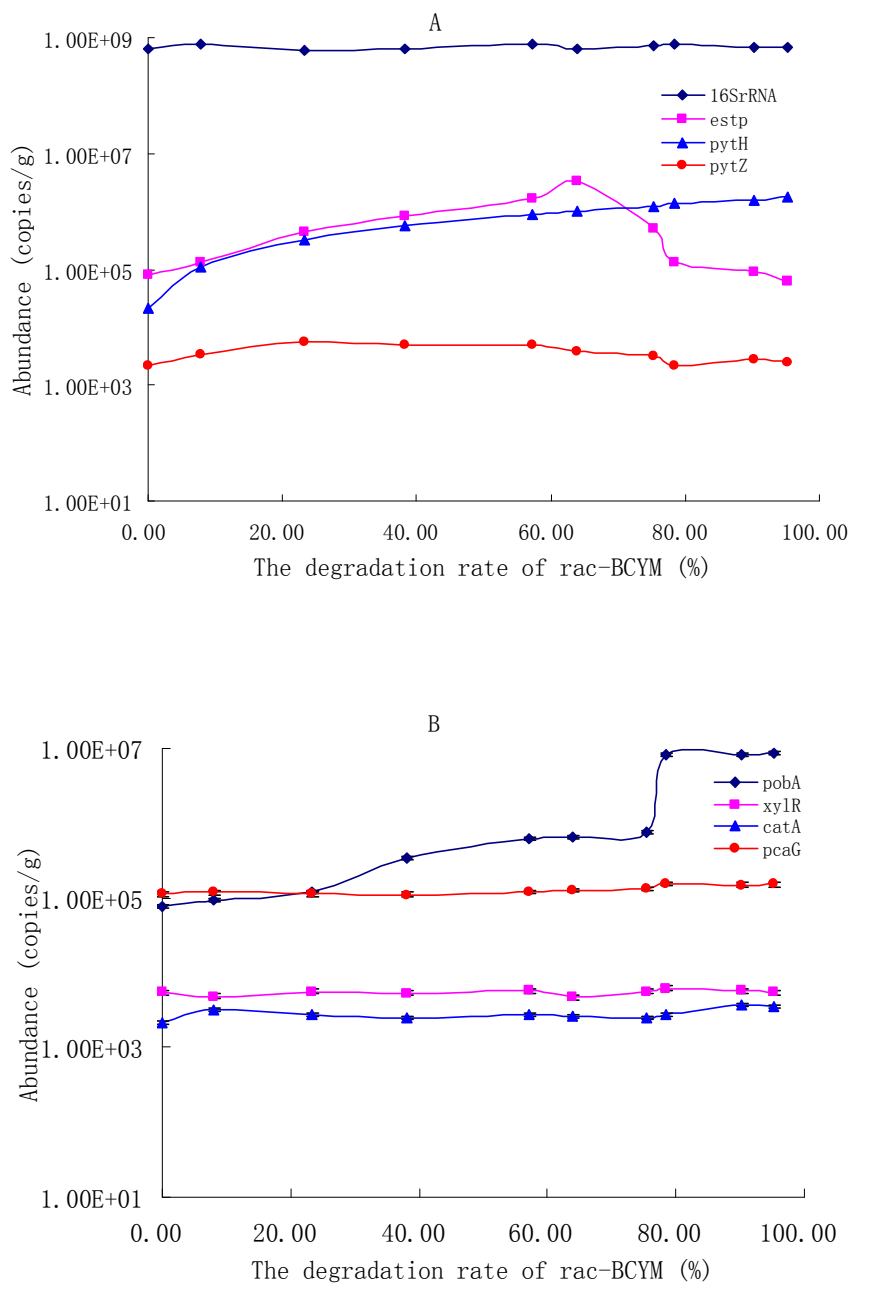

Fig S9: Absolute abundances of bacterial 16S rRNA and functional genes in Fuling soil 


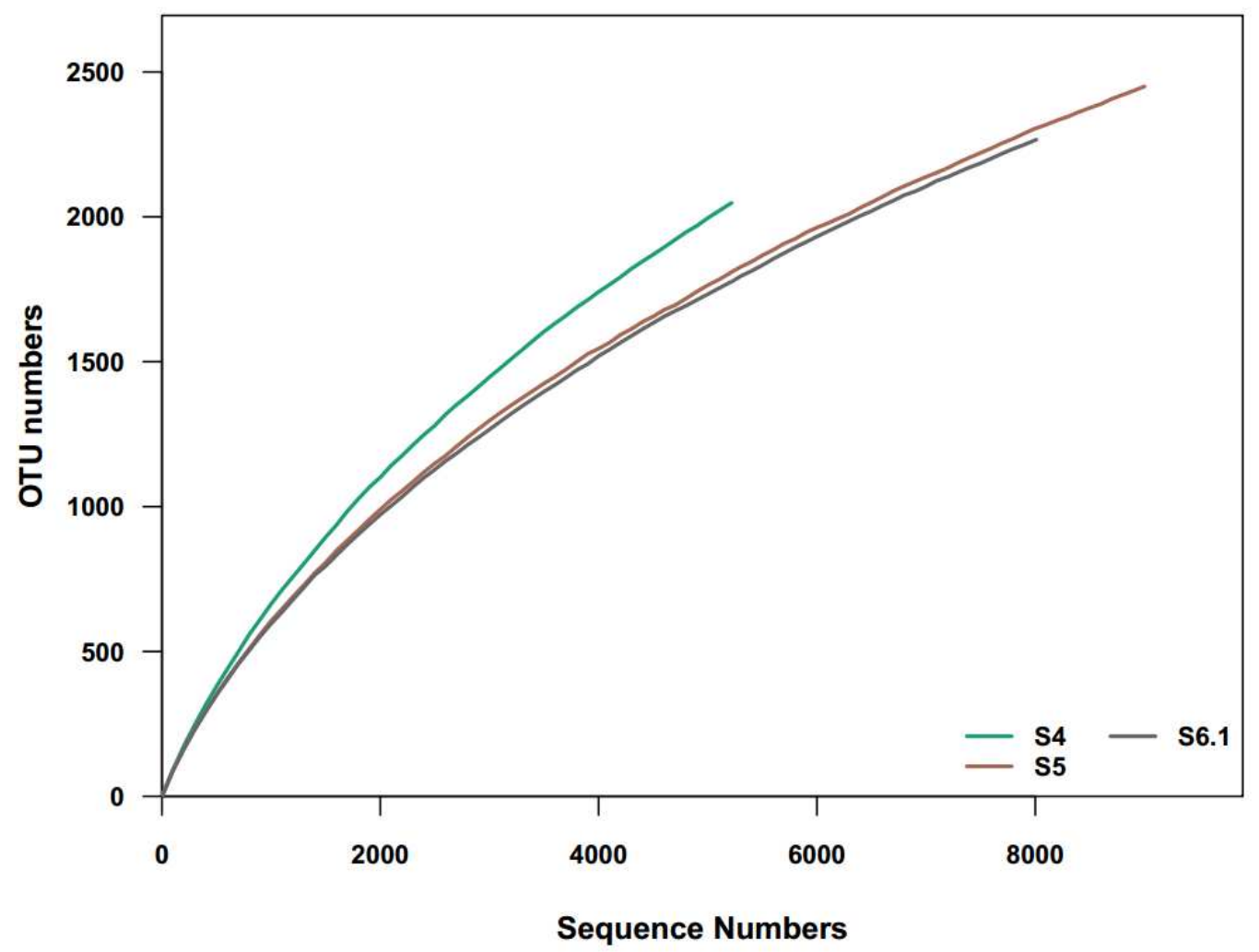

Fig. S10 Rarefaction curve of the three tested soil samples. S4, S5, S6.1 represent Fuling soil, Beijing soil and Changchun soil, respectively. 


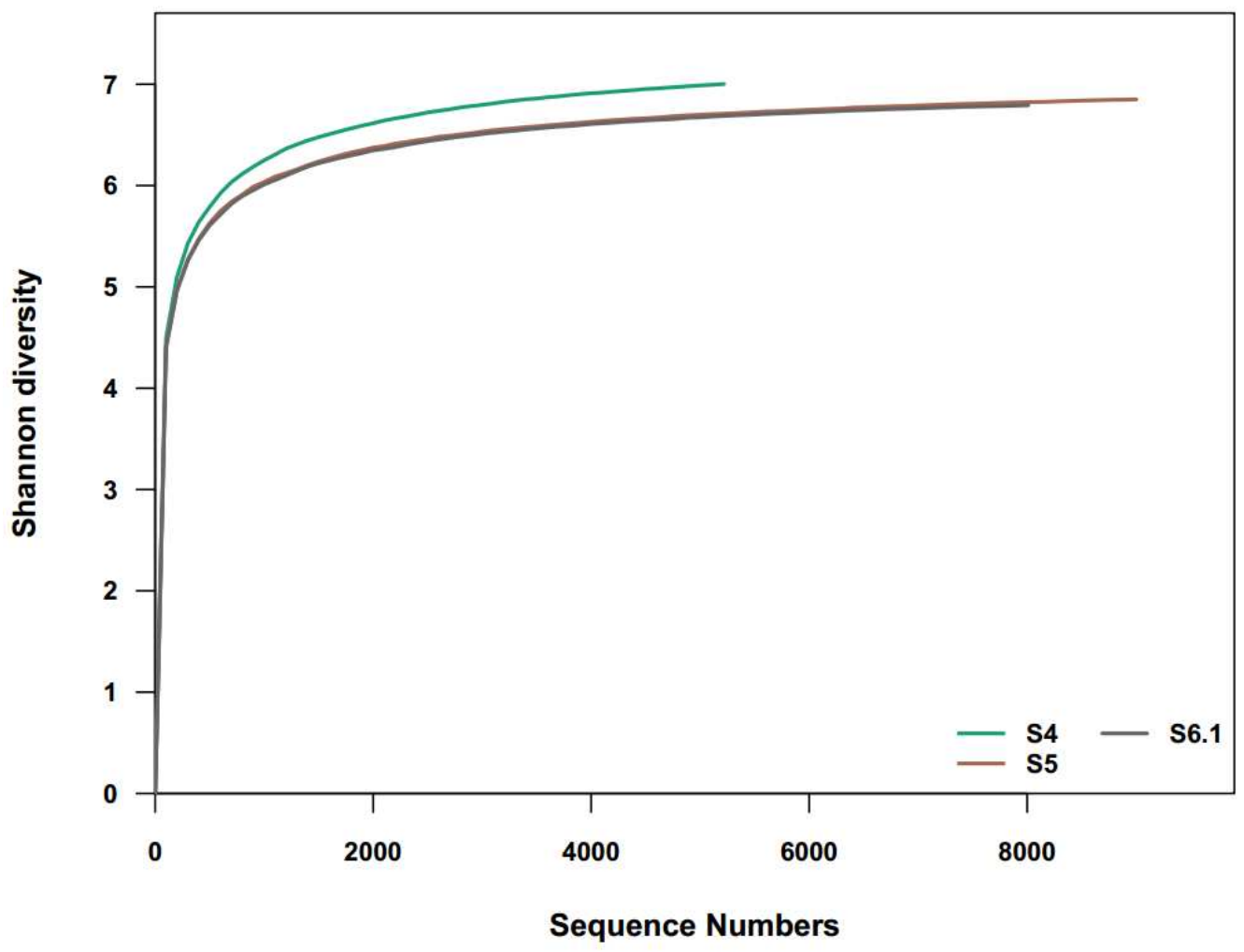

Fig. S11 Shannon curve of the three tested soil samples. S4, S5, S6.1 represent Fuling soil, Beijing soil and Changchun soil, respectively. 


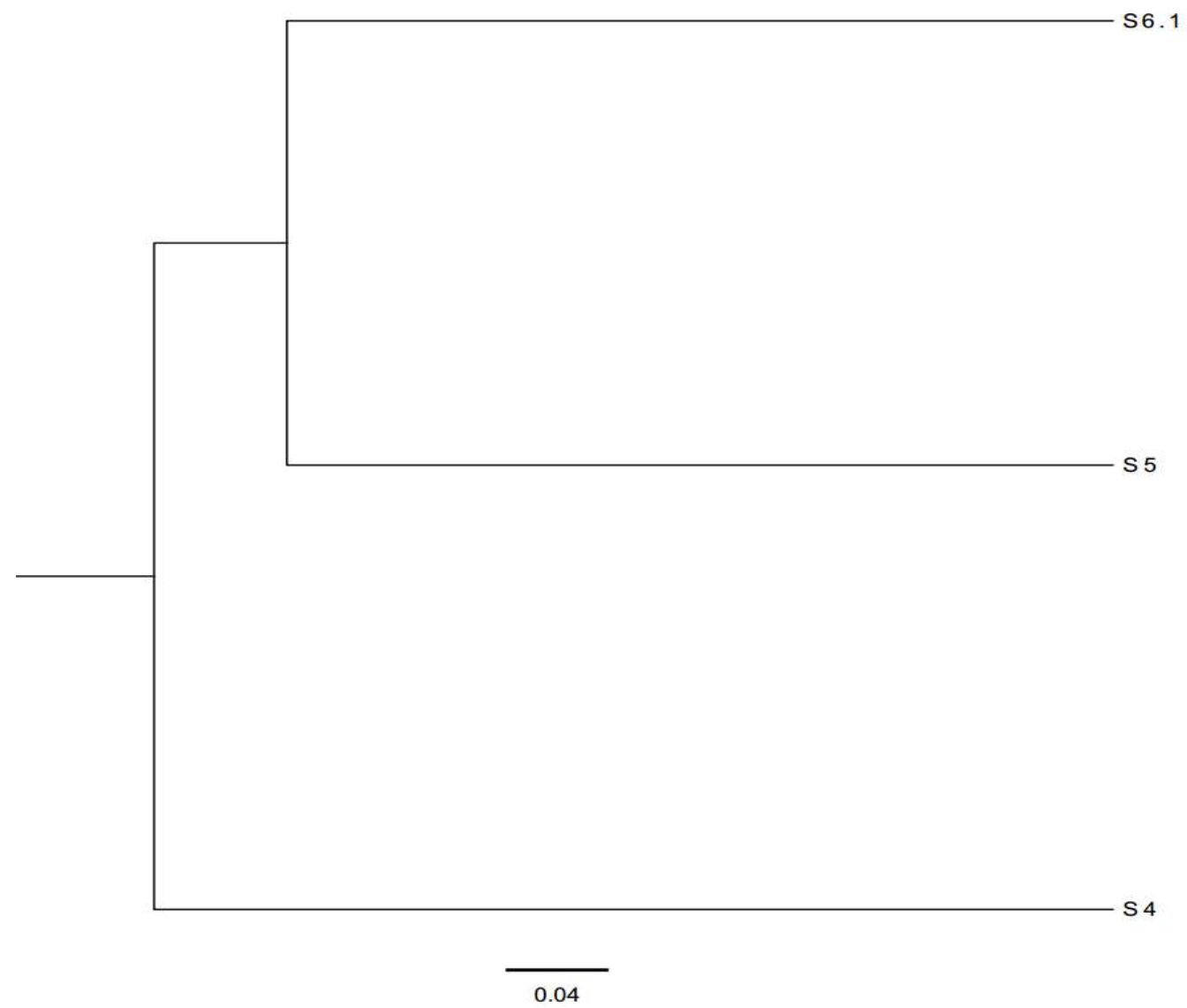

Fig. S12 The dendrogram of microorganisms community structure similarity among the tested soil samples. S4, S5, S6.1 represent Fuling soil, Beijing soil and Changchun soil, respectively. 


\section{Pcoa_unifrac_unweight}

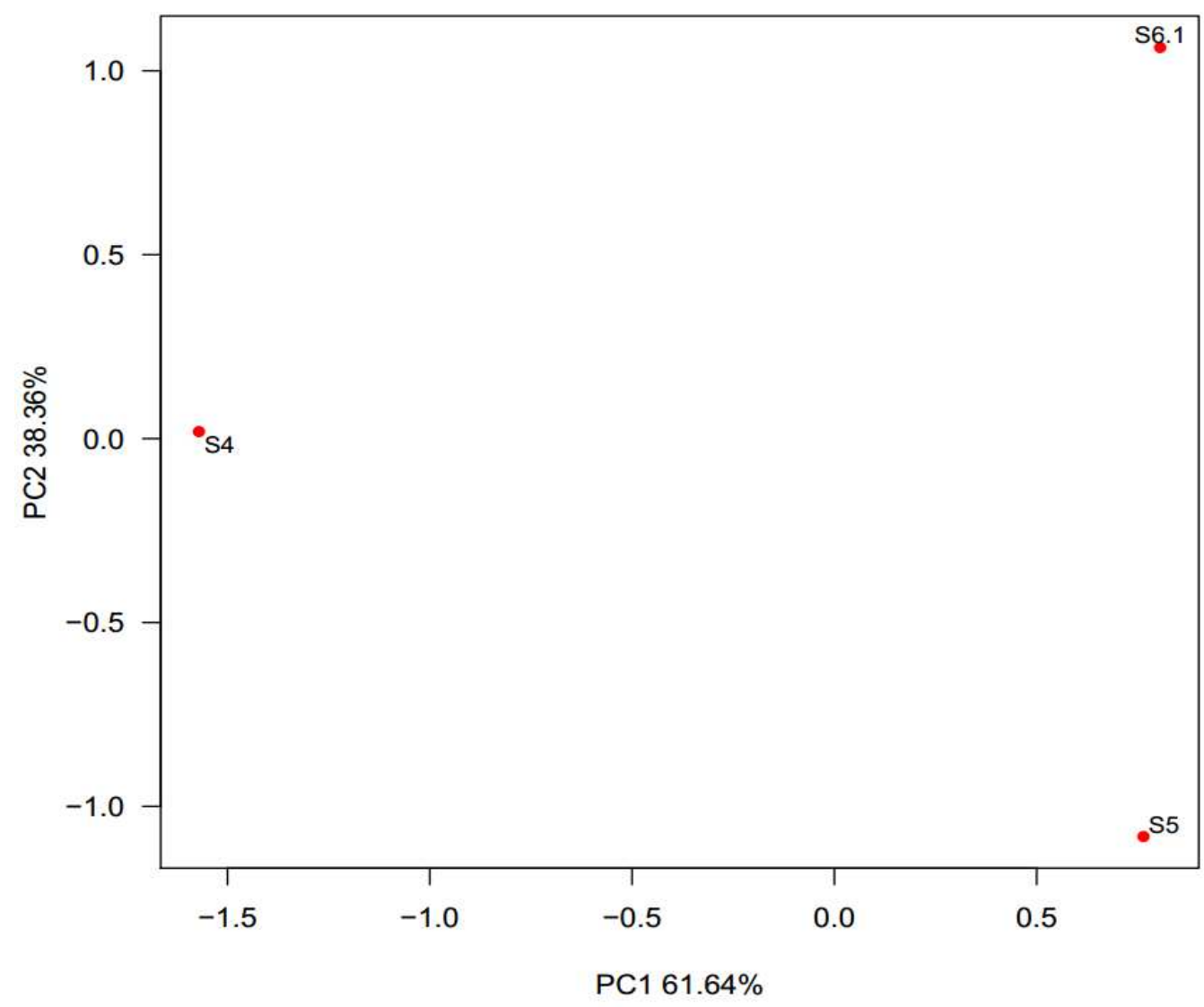

Fig. S13 Principal coordinates analysis of the three tested soil samples. S4, S5, S6.1 represent Fuling soil, Beijing soil and Changchun soil, respectively. 
Table S1 Primers used in the analysis of high-throughput sequencing

\begin{tabular}{ll}
\multicolumn{1}{c}{ Primer } & \multicolumn{1}{c}{ Sequences } \\
\hline Amplicon & TCGTCGGCAGCGTCAGATGTGTATAAGAGACAG (transposase sequences) \\
PCR Primer F & TACGGRAGGCAGCAG (forward primers) \\
Amplicon & GTCTCGTGGGCTCGGAGATGTGTATAAGAGACAG (transposase sequences) \\
PCR Primer R & AGGGTATCTAATCCT (reverse primers) \\
Index 1 & AATGATACGGCGACCACCGAGATCTACAC[i5] \\
Primer & TCGTCGGCAGCGTC \\
Index 2 & CAAGCAGAAGACGGCATACGAGAT[i7] \\
Primer & GTCTCGTGGGCTCGG \\
\hline
\end{tabular}


Table S2 Sequence statistics of high-throughput sequencing

\begin{tabular}{|c|c|c|c|c|c|c|c|c|}
\hline \multirow{2}{*}{ Sample } & \multirow{2}{*}{$\begin{array}{l}\text { Raw } \\
\text { reads }\end{array}$} & \multirow{2}{*}{$\begin{array}{l}\text { Low-quality } \\
\mathrm{N} \text { reads }\end{array}$} & \multirow{2}{*}{$\begin{array}{l}\text { Short } \\
\text { Reads }\end{array}$} & \multicolumn{2}{|c|}{ Homopolymer Analysis } & \multirow{2}{*}{\multicolumn{2}{|c|}{ minlength maxlength }} & \multirow{2}{*}{$\begin{array}{l}\text { average } \\
\text { length }\end{array}$} \\
\hline & & & & $>8$ Reads & Reads & & & \\
\hline SC & 75683 & 67264 & 0 & 641 & 8277 & 288 & 567 & $\begin{array}{c}410.615 \\
4806\end{array}$ \\
\hline SB & 93815 & 84277 & 0 & 766 & 9381 & 290 & 571 & $\begin{array}{c}410.443 \\
8396\end{array}$ \\
\hline SF & 53337 & 47948 & 0 & 248 & 5379 & 292 & 569 & $\begin{array}{c}413.275 \\
3401\end{array}$ \\
\hline
\end{tabular}


Table S3 Properties and locations of the three tested soils

\begin{tabular}{|c|c|c|c|c|c|c|}
\hline \multirow{2}{*}{ Soil site } & \multicolumn{3}{|c|}{ particle-size $(\%)$} & \multirow{2}{*}{ Soil texture } & \multirow{2}{*}{$\mathrm{pH}$} & \multirow{2}{*}{$\begin{array}{c}\text { Organic } \\
\text { matter } \\
(\%)\end{array}$} \\
\hline & sand & silt & clay & & & \\
\hline Changchun & $24.3 \pm 1.24$ & $62.1 \pm 1.12$ & $13.6 \pm 1.24$ & silt loam & $7.10 \pm 0.1$ & $2.25 \pm 0.12$ \\
\hline Fuling & $29.6 \pm 1.38$ & $50.3 \pm 1.22$ & $20.1 \pm 1.38$ & silt loam & $5.80 \pm 0.2$ & $1.49 \pm 0.18$ \\
\hline Changping & $48.4 \pm 1.22$ & $36.1 \pm 1.16$ & $15.5 \pm 1.42$ & sandy loam & $8.50 \pm 0.2$ & $2.05 \pm 0.16$ \\
\hline
\end{tabular}


Table S4 First-order rate constant $(\mathrm{k})$, half-life $\left(\mathrm{t}_{1 / 2}\right)$, and correlation coefficient $\left(\mathrm{R}^{2}\right)$ for the degradation of individual isomers in unsterilized soils.

\begin{tabular}{cccccc}
\hline Experiment & Incubated compound & Enantiomer & $\mathrm{k}\left(\right.$ day $\left.^{-1}\right)$ & $\mathrm{R}^{2}$ & $\mathrm{t}_{1 / 2}$ (days) \\
\hline SC2 & (+)-ACYM & (+)-ACYM & 0.0188 & 0.9741 & 36.86 \\
SC3 & (-)-ACYM & (-)-ACYM & 0.0155 & 0.9887 & 44.71 \\
SC4 & (-)-TCYM & (-)-TCYM & 0.0202 & 0.9851 & 34.31 \\
SC5 & (+)-TCYM & (+)-TCYM & 0.0236 & 0.9819 & 29.36 \\
SF2 & (+)-ACYM & (+)-ACYM & 0.0387 & 0.9689 & 17.91 \\
SF3 & (-)-ACYM & (-)-ACYM & 0.0327 & 0.9514 & 21.19 \\
SF4 & (-)-TCYM & (-)-TCYM & 0.0376 & 0.9857 & 18.43 \\
SF5 & (+)-TCYM & (+)-TCYM & 0.0395 & 0.9912 & 17.54 \\
SB2 & (+)-ACYM & (+)-ACYM & 0.0175 & 0.9232 & 39.60 \\
SB3 & (-)-ACYM & (-)-ACYM & 0.0140 & 0.9152 & 49.50 \\
SB4 & (-)-TCYM & (-)-TCYM & 0.0172 & 0.9483 & 40.29 \\
SB5 & (+)-TCYM & (+)-TCYM & 0.0190 & 0.9461 & 36.47 \\
\hline & & & & &
\end{tabular}


Table S5: standardized coefficient stepwise regression models between degradation rates and functional genes in Changchun, Fuling and Beijing soils soil $(\mathrm{n}=10)$

\begin{tabular}{|c|c|c|c|c|}
\hline Soil & The regression equation & $\mathrm{R}^{2}$ & $\mathrm{P}$ & $\mathrm{n}$ \\
\hline \multirow[t]{7}{*}{$\mathrm{SC}_{1}$} & $\mathrm{BCYM}=0.498 \mathrm{H}+0.509 \mathrm{~A}$ & 0.995 & 0.002 & 10 \\
\hline & $\mathrm{ACYM}=0.434 \mathrm{H}+0.572 \mathrm{~A}$ & 0.993 & 0.003 & 10 \\
\hline & $\mathrm{TCYM}=0.538 \mathrm{H}+0.468 \mathrm{~A}$ & 0994 & 0.003 & 10 \\
\hline & $(+)-\mathrm{ACYM}=0.513 \mathrm{H}+0.494 \mathrm{~A}$ & 0.996 & 0.001 & 10 \\
\hline & $(-)-\mathrm{ACYM}=0.324 \mathrm{H}+0.673 \mathrm{~A}$ & 0.977 & 0.017 & 10 \\
\hline & $(-)-\mathrm{TCYM}=0.593 \mathrm{H}+0.413 \mathrm{~A}$ & 0.995 & 0.006 & 10 \\
\hline & $(+)-\mathrm{TCYM}=0.487 \mathrm{H}+0.518 \mathrm{~A}$ & 0.992 & 0.005 & 10 \\
\hline \multirow[t]{7}{*}{$\mathrm{SF}_{1}$} & $\mathrm{BCYM}=0.472 \mathrm{H}+0.557 \mathrm{~A}$ & 0.956 & 0.010 & 10 \\
\hline & $\mathrm{ACYM}=0.454 \mathrm{H}+0.574 \mathrm{~A}$ & 0.956 & 0.011 & 10 \\
\hline & $\mathrm{TCYM}=0.520 \mathrm{H}+0.510 \mathrm{~A}$ & 0.957 & 0.006 & 10 \\
\hline & $(+)-\mathrm{ACYM}=0.397 \mathrm{H}+0.627 \mathrm{~A}$ & 0.950 & 0.027 & 10 \\
\hline & $(-)-\mathrm{ACYM}=0.449 \mathrm{H}+0.577 \mathrm{~A}$ & 0.951 & 0.015 & 10 \\
\hline & $(-)-\mathrm{TCYM}=0.526 \mathrm{H}+0.503 \mathrm{~A}$ & 0.957 & 0.007 & 10 \\
\hline & $(+)-\mathrm{TCYM}=0.507 \mathrm{H}+0.522 \mathrm{~A}$ & 0.954 & 0.007 & 10 \\
\hline \multirow[t]{7}{*}{$\mathrm{SB}_{1}$} & $\mathrm{BCYM}=0.428 \mathrm{H}+0.580 \mathrm{~A}$ & 0.975 & 0.024 & 10 \\
\hline & $\mathrm{ACYM}=0.514 \mathrm{H}+0.500 \mathrm{~A}$ & 0.985 & 0.003 & 10 \\
\hline & $\mathrm{TCYM}=0.465 \mathrm{H}+0.539 \mathrm{~A}$ & 0.966 & 0.032 & 10 \\
\hline & $(+)-\mathrm{ACYM}=0.501 \mathrm{H}+0.5134 \mathrm{~A}$ & 0.985 & 0.003 & 10 \\
\hline & $(-)-\mathrm{ACYM}=0.518 \mathrm{H}+0.494 \mathrm{~A}$ & 0.982 & 0.006 & 10 \\
\hline & $(-)-\mathrm{TCYM}=0.372 \mathrm{H}+0.630 \mathrm{~A}$ & 0.064 & 0.010 & 10 \\
\hline & $(+)-\mathrm{TCYM}=0.487 \mathrm{H}+0.514 \mathrm{~A}$ & 0.959 & 0.038 & 10 \\
\hline
\end{tabular}

BCYM, ACYM, TCYM, (+)-ACYM, (-)-ACYM, (-)-TCYM and (+)-TCYM represent the degradation rates of BCYM, ACYM, TCYM, (+)-ACYM, (-)-ACYM, (-)-TCYM and (+)-TCYM, respectively. In $(p o b A)$ and $\ln (p y t H)$ were abbreviated as $\mathrm{A}$ and $\mathrm{H}$, respectively. $p o b A$ and $p y t H$ represent the absolute abundances of $p o b A$ and $p y t H$. 